\title{
The European Society for Engineering and Medicine (ESEM) fills a need in Europe
}

\author{
Jan E.W. Beneken Ph.D
}

President, ESEM

\section{Introduction}

In February 1991, the European Society for Engineering and Medicine was founded in Nice, France, after consultation with some European Societies, to assure fruitful cooperation. This paper describes the objectives of ESEM and the historical context; its position with respect to related European and national societies will be explained. The internal organisation of ESEM reflects its intention to function in close relation with individual members, while both existing societies, industries and other organisations can join ESEM as associate member. Some of the achievements and further plans will be presented.

\section{History}

The relationship between engineering and medicine in Europe has a long and fruitful history. Many countries established strong and active societies, some of which attracted foreign members and/or organised interesting open conferences. The International Federation for Medical and Biological Engineering (IFMBE) brought many of these national organisations together and sponsored many conferences and other activities in Europe.

The Commission of the European Communities (CEC), from the beginning, recognised the importance of this field for Europe and allowed a large portion of its budget for research and development to be used for biomedical engineering (BME) projects; from the budget of the fourth Medical and Health Research Programmes as directed by the DG XII through the eighties and early nineties, approximately $25 \%$ was spent in this area of interest. Towards the end of the fourth Programme, 1200 research centers distributed all over Europe were active in 30 concerted actions in the field of biomedical engineering. The latest programme BIOMED of the CEC also recognises medical technology in one of its target areas.

During the course of such programmes the researchers from different institutes and sometimes from industry are offered opportunities to meet their immediate colleagues as they participate in the concerted actions. A number of such collaborative actions seem to continue after the termination of EC funding. Furthermore, it is obvious that networks established under such European programmes will have a dynamically vary- 
ing composition; participants come and go depending on the targets being emphasised in the programme and on the concomitant concerted actions or consortia.

The group of initiators of ESEM (the present Executive Board and Board of Directors) saw the necessity to try and maintain those networks already established and possibly expand them into different fields. It was considered an enormous waste of the invested energy, time and money if the European R \& D community would not be offered a regular opportunity to maintain, renew, or expand its various relationships. Although the new Society would try and act as an information channel between the EC and the R\&D community, it should be independent.

Based on our past experience we also realised the importance of creating a proper and obvious balance between people with a so-called "exact" scientific background (engineers, physicists, mathematicians, computer and information scientists) and those with a medical and/or biological background. Furthermore, without giving consideration to the potential social impact of our R\&D activities, we run the risk either of drifting towards irrelevant areas of research or of finding a society which is not ready or inclined to accept the products of our efforts.

Membership should be open to people from all European countries. There is no reason to let international political and economic constructs set limits on an international scientific society.

In preparation of the foundation of the new society, we invited representatives of different $\mathrm{Eu}$ ropean societies and federations for a meeting in December 1990 with whom we frankly discussed our objectives and intentions. This fruitful discussion even resulted in an adaptation of the name we had planned for the new society. It was obvious that we had to limit the participation in that meeting to European organisations and could not extend the invitation to all national organisations.

In February 1991, during the first European Conference on Biomedical Engineering which was held in Nice, the European Society for Engineering and Medicine was formally made public in a meeting attended by a few hundred people. In February 1992, ESEM received official Royal recognition under Belgian law. This decision was officially published in August 1992.

\section{Objectives and their implementation}

The objectives of ESEM will follow logically from its historical development and are clearly defined by Article 4 of the Statutes of ESEM:

- To promote cultural and scientific exchanges between engineers of all disciplines, related industries and the medical profession, on a European level.

- To encourage the creation of European research networks as well as European clinical networks, in order to reinforce, by a wider dissemination of information, European potentialities in Engineering and Medicine and to participate in their assessment.

- To contribute to the promotion of European Community programmes in Engineering and Medicine fields.

- To organise specific training courses for engineers, medical and paramedical staff, as well as for health administrators.

- To cooperate closely with all similar international organisations and with national bodies concerned with Engineering and Medicine.

Article 4 of the Statutes of ESEM continues to indicate means for reaching these objectives:

To reach those goals, European meetings, in accordance with the relevant bye-laws shall be regularly organised with contributions from specialists in medical and biological disciplines, engineers, physicists and information scientists from universities, hospitals, research centres and industries, in such a way that cross-disciplinary exchanges shall be stimulated.

As a further means of improving scientific communication and educational training, a European Journal, covering the state of the art of engineering and medical topics, new knowledge and new technology, as well as new industrial products, shall be created.

Other activities for the advancement of health care through the application of all kinds of engineering and the development of industrial activities shall be strongly encouraged. 


\section{Internal organisation}

Although the citations from the Statutes sound rather formal, they clearly indicate the intentions of ESEM. The organisational structure of ESEM as reflected in the bye-laws, accurately represents these intentions. The Council of ESEM is assisted by four strong committees:

- Publication Committee, with responsibility both for Technology and Health Care and for ESEM News, the information newsletter for the members.
- Conference Committee, with the prime responsibility for setting up the organisation of the biennial European conference and eventually for smaller topical workshops.

- Membership Committee, with responsibility for identifying and recruiting new members. We accept individuals with the proper education and training who subscribe to our objectives. National and international societies both medical and technical, hospitals and other institutes in the area of engineering and medicine can join ESEM as associate members. The relations between ESEM and

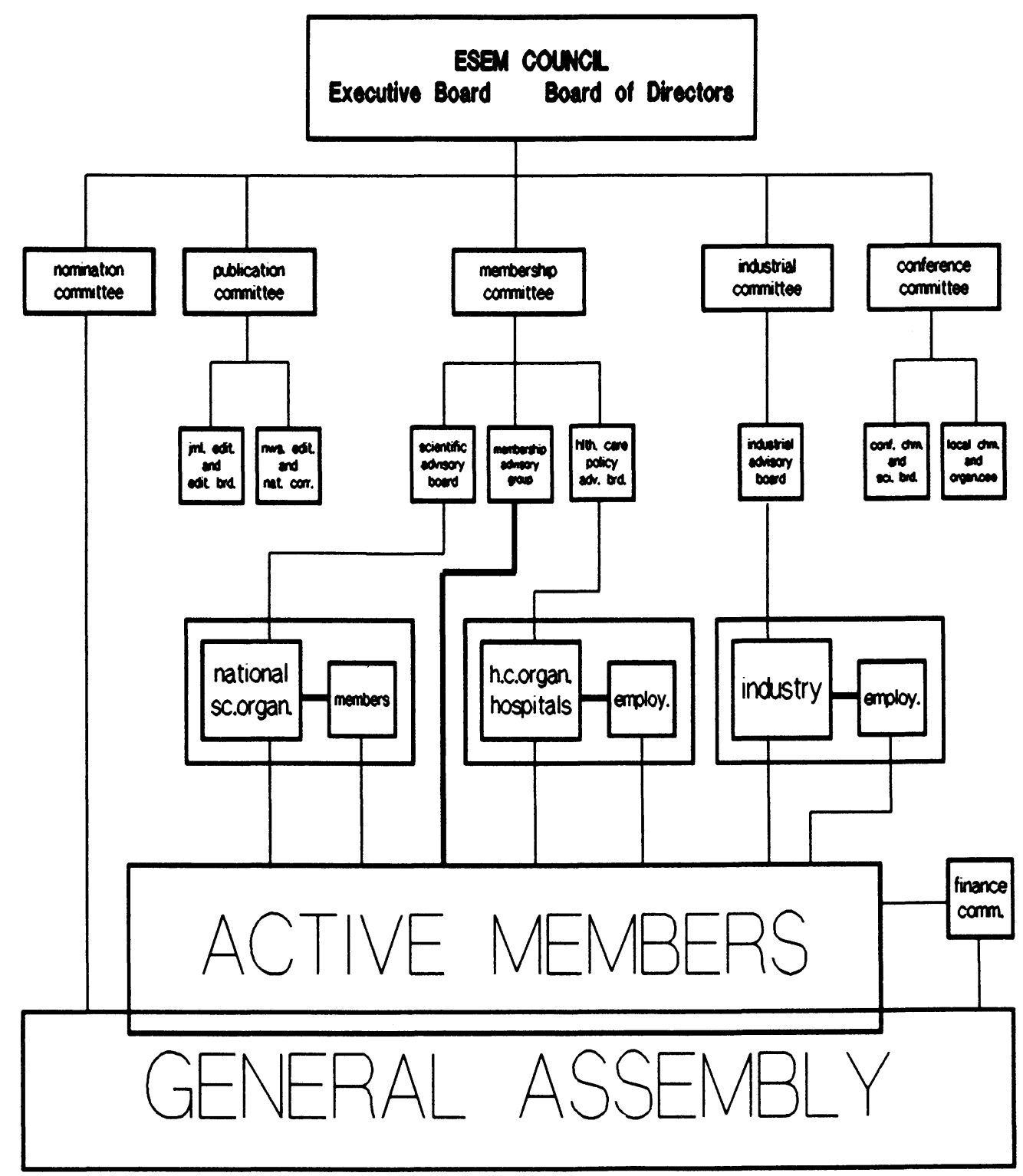

Fig. 1. Internal organisation of the European Society for Engineering and Medicine. 
associate members are maintained by representatives who otherwise have a similar status as individual members. (See also under "Relations...") - Industrial Committee which identifies and recruits industrial members, who also communicate through their representatives.

In order to facilitate the communication between ESEM and its associate members, who by nature, represent a large number of people, we have established three Advisory Boards in which each associate member can appoint his representative and which will meet in conjunction with the Conference. It is recognised that the countries of Europe have completely different historical and cultural backgrounds and for this reason their inhabitants may have different interests and priorities. The Scientific Advisory Board, is the place for discussing such matters and the role ESEM can play in strengthening the European cooperation. Also, it is our intention to make this Board instrumental in generating a European calendar of events, reflecting both international and relevant national events in the broad field of Engineering and Medicine.

The Industrial Advisory Board will encourage the special interests of the industry in the choice of conference topics, smaller topical workshops or special courses.

The Health Care Policy Advisory Board can develop into an exchange and discussion forum concerning the differences between national policies and health care approaches, and their impact on R\& D in the field of Engineering and Medicine.

It is obvious that the individual active members will form the ultimate decision-making body of ESEM. The General Assembly, therefore, will meet every two years in conjunction with the European Conference. The organisational chart is given in Fig. 1, to facilitate the understanding of the internal structure of ESEM.

\section{Position relative to existing national and Euro- pean societies}

From the objectives it will be clear that ESEM will act at the European level, where it will organise meetings, publish a Journal and a Newsletter and develop activities to stimulate cross-disciplinary communication in all fields of medicine and engineering in order to strengthen quality and the position of its R\&D in Europe.

We intend to do this in full recognition of and in close collaboration with the national societies. Many of them are already strong and have developed international relationships; ESEM will be a platform for extending such relationships. For other societies, ESEM may open a window to the European scene. In no way does ESEM want to interfere or compete with these national societies; we believe that their existence and success constitute the vital elements for further European development. As some countries have not (yet) established a society in the field of engineering and medicine, ESEM can be the primary home organisation for researchers and developers from those countries.

Many existing European societies and/or federations that cover certain specialised areas from the vast field of engineering and medicine are flourishing and they too serve an important need by offering communication opportunities in those highly specialised fields.

Progress in research and development is often enhanced by cross-fertilisation, i.e. by translating methods and ideas from one specialised field into a different field. This requires exposure to those methods and ideas and ESEM is creating opportunities for these exchanges and communications between many disciplines, without a priori specialising or subdividing the field.

To avoid high membership fees for individuals, we provided the possibility of becoming an Associate member of ESEM to interested national and international organisations whose members will have to pay only a reduced fee to ESEM, while maintaining the full rights of a regular member. Each associate member will also have the right to appoint a number of their members as representatives in ESEM; they too will have the same rights as regular members.

The above mentioned Scientific Board also demonstrates our intention for collaboration. Combining ESEM meetings with national or other international meetings may prove another interesting means for mutual support. We hope to 
develop jointly additional ways for fruitful collaborations.

\section{What has been accomplished?}

Much work, time and energy has been invested by many Council and other members, into ESEM before and during its first year and a half. It is with great pride that we present the first issue of the official Journal of the European Society for Engineering and Medicine. This in itself is a great achievement and I hope that this Journal will find its way into the hands of a great many European researchers of different disciplines, and that all those who subscribe to the principles presented above, will submit their papers and share their knowledge and insight.

In April 1993, the Second European Conference on Engineering and Medicine will be held in Stuttgart, Germany. The invited speakers can be considered world leaders in their fields; together with the many submitted papers of good quality we expect this conference to be another success, with ample and varied opportunities for presenting and discussing scientific work. The broad disciplinary participation will be unique for the discussion of the social impact of scientific achievements in engineering and medicine.

ESEM News, our newsletter, has contained in the first few issues extremely useful information concerning meetings, programme opportunities of the CEC and background information about the growing ESEM organisation. We welcome the contributions of our members and subscribers who want to announce activities relevant to the European readership. We will seek to have correspondents in all European countries to guarantee good coverage of important events and news items.

The backbone of a society like ESEM is its members. Our membership is continuously grow- ing and reached over 260 active members in September of 1992 who together with 5 associate members and more then 10 industrial members constitute the initial believers in the ideals of ESEM. We expect a continuation of our growth now that the Journal has appeared which is free for ESEM members, and with the Stuttgart meeting immediately ahead of us where ESEM will again show its particular strength.

\section{Future activities of ESEM}

It must be clear that we will continue to put much effort into bringing the Journal to a high scientific level, with contributions about the latest achievements at the interface between medicine and engineering, with additional attention to national health care policies, industrial policies and social consequences.

The biennial conferences will cover essentially the same topics, although each conference will have its own colour by emphasising specific topics. We remain open for suggestions to hold either the conference, or smaller topical meetings, in conjunction with national or other international organisations. The ESEM News will serve as a reliable vehicle for distributing relevant information about European events and about CEC programmes, their objectives and ways for filing applications.

We expect ESEM to serve as a large platform in Europe with its connections to national, international and world organisations thus recognising the need and offering the opportunities for much cross-disciplinary communication in the field of engineering and medicine for the benefit of health care and public health in Europe.

Eindhoven January, 1993 